\title{
Temozolomide treatment in pituitary tumor causing Cushing's Disease resistant to conventional therapy - Case report
}

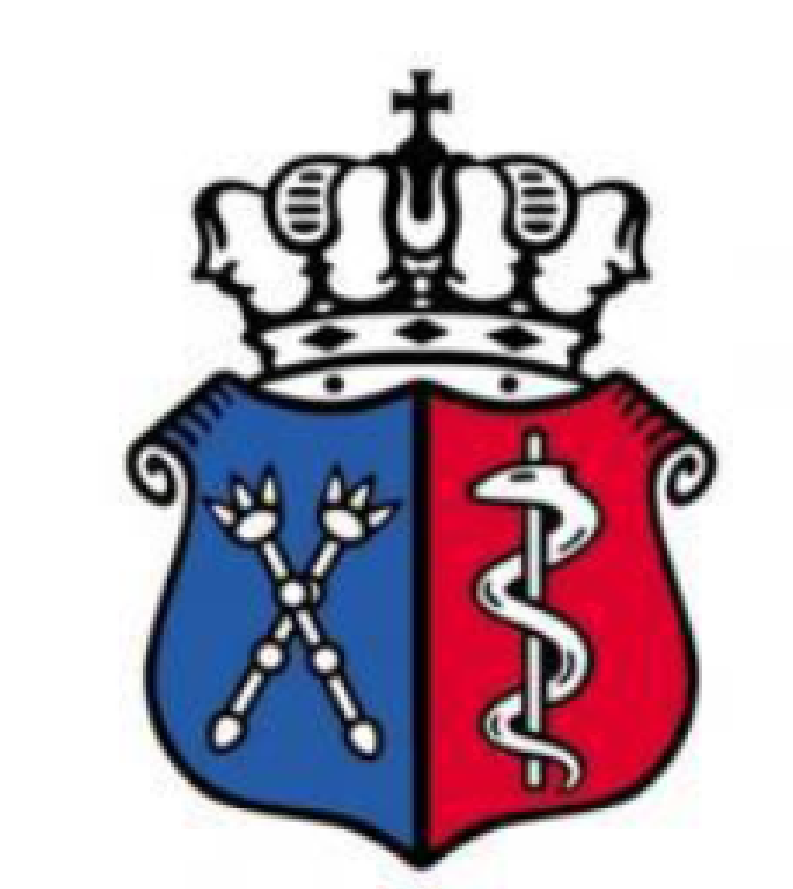

\author{
Authors: A. Gilis-Januszewska, J. Pantofliński, R. Turek-Jabrocka, G. Sokołowski, M. Wilusz, D. Pach, A \\ Hubalewska-Dydejczyk
}

Hospital: Chair and Department od Endocrinology, Jagiellonian University, Medical College, Krakow, Poland University Hospital, Krakow, Poland

\section{OBJECTIVES}

The management of pituitary tumors causing Cushing's Disease are a multidisciplinary challenge to clinicians with neurosurgery as a first line treatment followed by the radiotherapy and pharmacotherapy including chemiotherapy. Such tumors are difficult to treat with high rate of recurrence. To date only 25 patients with Cushing Disease treated with the new alkylating agent temozolamide (TMZ) have been reported.

\section{GRAPHS AND TABELS}
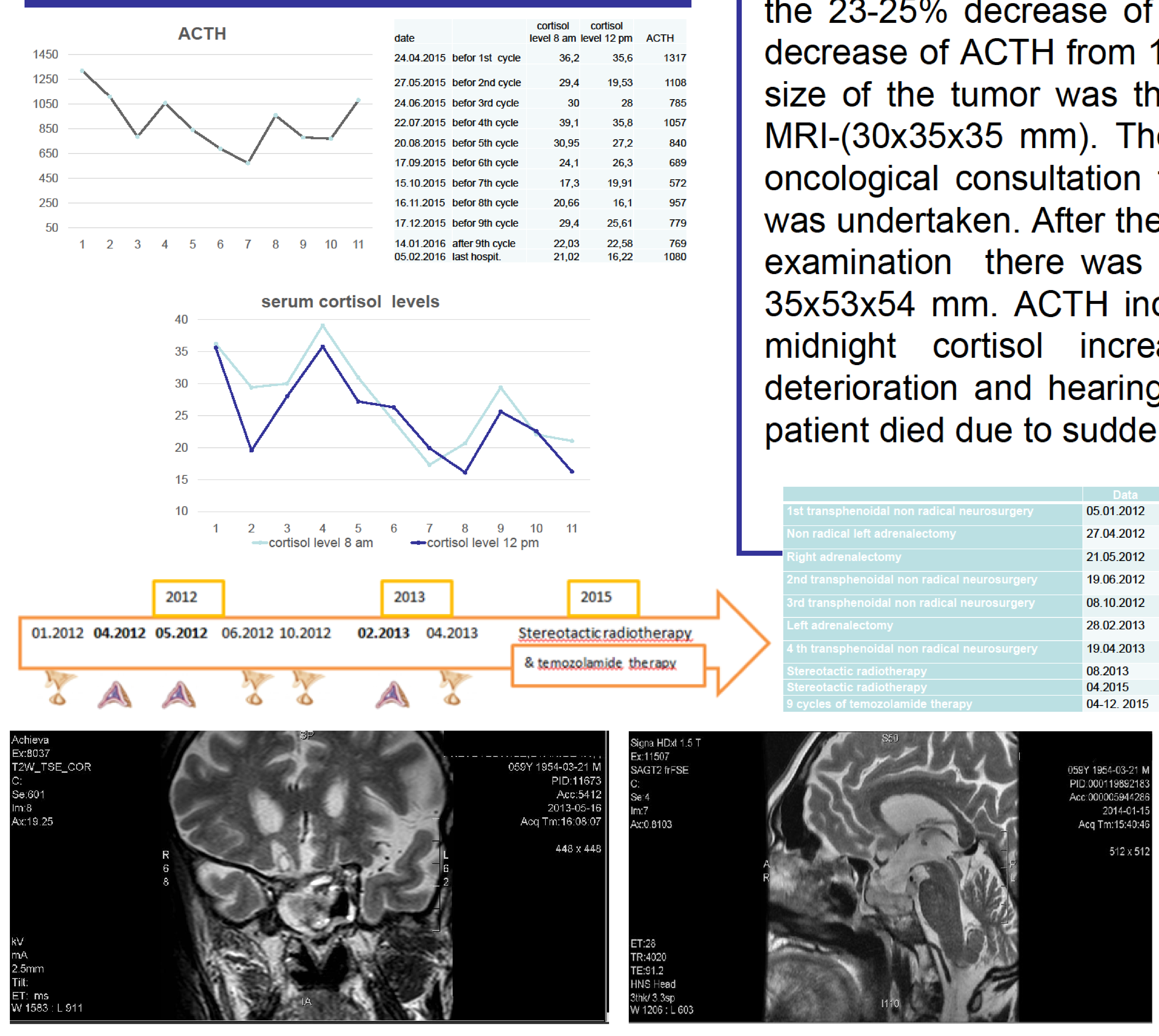

\section{CONCLUSIONS}

The treatment with TMZ was effective and safe during first 6 cycles with progression observed during the continuation of the treatment. Further studies on the effectiveness of $\mathrm{TMZ}$ and other agents should be continued in patients with corticotrophin tumors resistant to conventional therapy.

\section{CASE PRESENTATION}

Temozolomide (TMZ) is an alkylating chemotherapeutic agent that has recently been used in some cases as a new therapeutic tool for pituitary aggressive adenomas. In this report, we present the case of TMZ treatment in a 61 year old male patient who was diagnosed as Cushing's Disease in the course of pituitary macradenoma in 2011. Patient underwent four transphenoidal non radical neurosurgeries $(2012,2013)$ with rapid tumor progression, with postsurgical insufficiency of gonadal and thyroid axis, repeated non radical bilateral adrenalectomy $(2012,2013)$ and stereotactic radiotherapy and gamma knife surgery $(2013,2015)$. Histopatological examination revealed macroadenoma with high cell polimorfism and presence of the Crooke's cells. Patient has been treated with $600 \mathrm{mg}$ of ketokonazol. From 2015 treated with 6 cycles of temozolamide with important clinical improvement with the $23-25 \%$ decrease of morning and midnight cortisol and the decrease of ACTH from 1317 to $689 \mathrm{pg} / \mathrm{ml}$. In the control MRI the size of the tumor was the same as in the previous examination

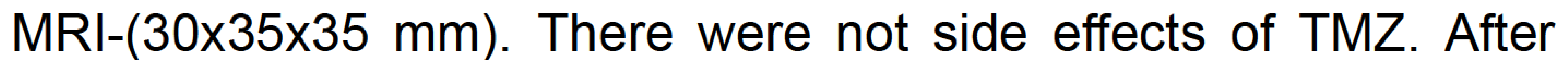
oncological consultation the decision to continue TMZ treatment was undertaken. After the 9th cycle of TMZ in XII 2015 in the PET examination there was an increase in the size of the tumor to $35 \times 53 \times 54 \mathrm{~mm}$. ACTH increased to $779 \mathrm{pg} / \mathrm{ml}$, with morning and midnight cortisol increase. The clinical status and sight deterioration and hearing loss were observed. In February 2016 patient died due to sudden deterioration of the clinical status.
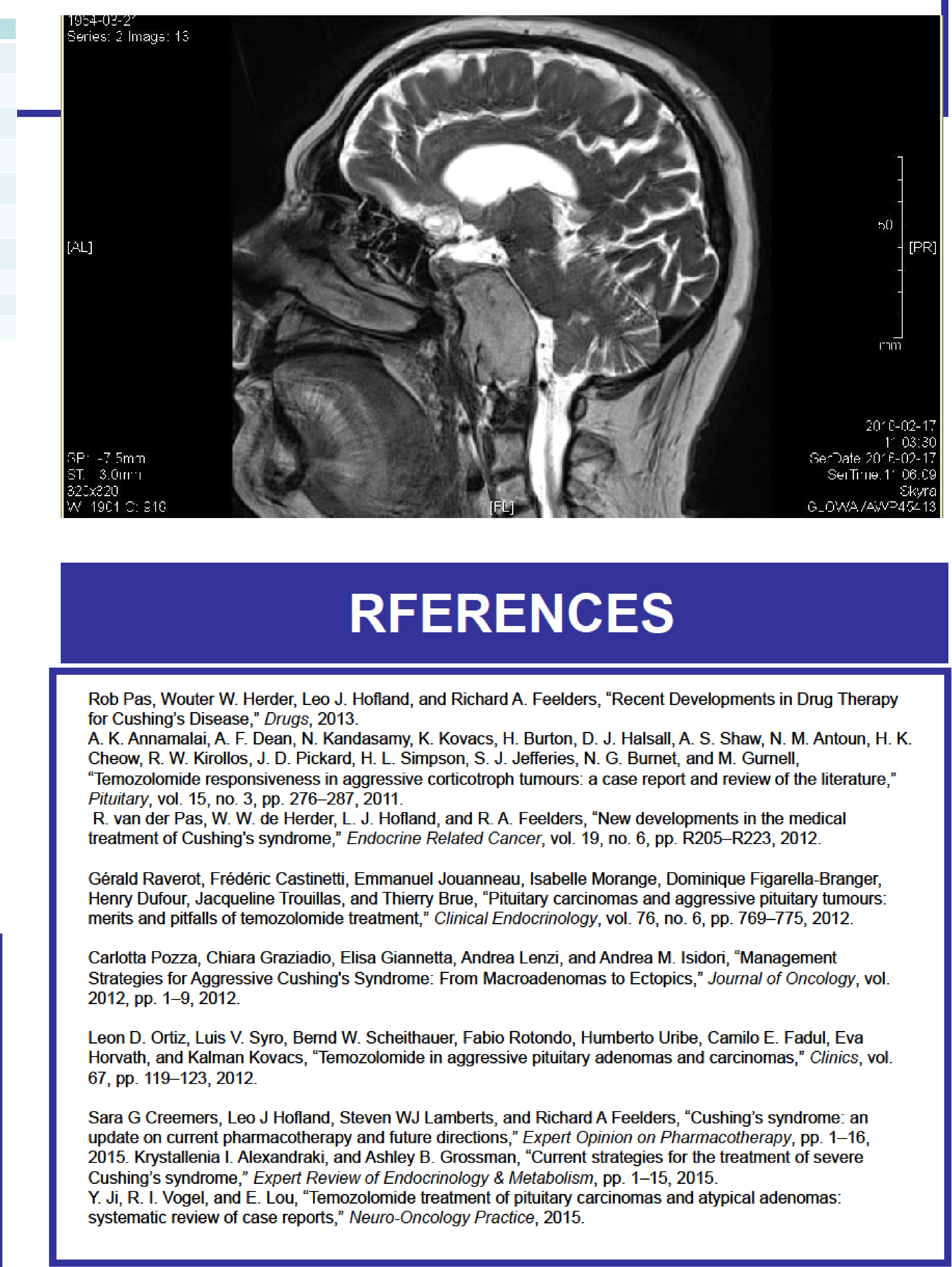